\title{
RESULTS OF CALCULATION-EXPERIMENTAL INVESTIGATIONS OF ELECTRO- THERMAL RESISTIBILITY OF SHEET STEEL SAMPLES TO ACTION OF RATIONED COMPONENTS OF PULSED CURRENT OF ARTIFICIAL LIGHTING
}

Purpose. Calculation and experimental researches of the electro-thermal resistibility of the steel sheet samples to action standard pulse current components of the artificial lightning with amplitude-time parameters (ATP), corresponded the requirements of normative documents of USA for SAE ARP 5412 \& SAE ARP 5416. Methodology. Electrophysics bases of technique of high tensions and large impulsive currents (LIC), and also scientific and technical bases of planning of devices of high-voltage impulsive technique and measuring in them LIC. Current amplitude $I_{m A}= \pm 200 \mathrm{kA}$ (with a tolerance of $\pm 10 \%$ ); current action integral $J_{A}=2 \cdot 10^{6} A^{2} \cdot s$ (with a tolerance of $\pm 20 \%$ ); time, corresponding to the amplitude of the current $I_{m A}, t_{m A} \leq 50$ microseconds; the duration of the current flow $\tau_{p A} \leq 500$ microseconds. Results. The results of the evaluation of the calculated and experimental studies of electro-thermal resistance of the samples of plates measuring $0,5 \mathrm{~m} \times 0,5 \mathrm{~m}$ stainless steel $1 \mathrm{~mm}$ thickness to the action on them artificial lightning impulse currents with rationed ATP on the requirements of normative documents of USA for $S A E$ ARP 5412 \& SAE ARP 5416. A pulse A-component have a first amplitude $192 \mathrm{kA}$, the corresponding time of $34 \mu \mathrm{s}$, and the duration aperiodic component amplitude 804 A, corresponding to the time 9 ms. It has been shown that the long $C$-component current of artificial lightning can lead to keyhole these samples. The diameter of the holes in this thin steel sheet, which is formed during the flow of current $C$ - components can reach $15 \mathrm{~mm}$. The results of calculation and experiment agree within $28 \%$. Originality. For the first time in world practice on the generator large pulsed currents experimental studies of resistibility of sheet steel samples to the action of artificial lightning currents with critical parameters. Practical value. Using the results obtained in the practice of lightning protection will significantly improve the functionality and fire safety of different objects in conditions of exposure to linear lightning. References 15 , figures 15 , tables 5.

Key words: main components of lightning current, impulse current generator of artificial lightning, flat steel sample, electrothermal resistibility to lightning..

Приведены результаты оценочных расчетных и экспериментальных исследований электротермической стойкости опытных образцов пластин размером 0,5 м $\times 0,5$ м из нержсавеющей стали толщиной 1 мм к воздействию на них импульсных токов искусственной молнии с нормированными по требованиям нормативных документов США SAE ARP 5412 и SAE ARP 5416 амплитудно-временными параметрами (АВП). Использовались колебательная импульсная A- компонента с первой амплитудой 192 кА, соответствующей времени 34 мкс, и апериодическая длительная Скомпонента амплитудой 804 A, соответствующей времени 9 мс. Показано, что длительная С- компонента тока искусственной молнии с нормированными АВП может приводить к сквозному проплавлению указанных образцов. Библ. 15 , рис. 15 , табл. 5 .

Ключевые слова: основные компоненты тока молнии, генератор импульсного тока искусственной молнии, плоский стальной образец, электротермическая молниестойкость.

Introduction. For direct impacts of linear lightning, developing in an air atmosphere of the Earth with an average rate of 100 discharges per second [1,2], in the high-altitude engineering structures placed on the earth's surface, the amplitude-time parameters (ATP) pulsed current in the plasma channel its discharge may taking dangerous both for external structural elements, as well as electrical power and low voltage electronic equipment contained within these structures. According to the requirements of the current normative US SAE ARP 5412 and SAE ARP 5416 documents [3, 4], relating mainly to be exposed to direct lightning strikes aerospace objects, the pulse current of the lightning discharge consists of two main components: the pulse $A$ - and long-term $C$ components. This ATP of normalized pulse $A$ components of lightning current according to $[3,4]$ take the following numerical values: current amplitude $I_{m A}= \pm 200 \mathrm{KA}$ (with a tolerance of $\pm 10 \%$ ); current action integral $J_{A}=2 \cdot 10^{6} \mathrm{~A}^{2} \cdot \mathrm{s}$ with (with a tolerance of $\pm 20 \%$ ); time corresponding to the amplitude of the current $I_{m A}$, $t_{m A} \leq 50 \mu \mathrm{s}$; the duration of the current flow $\tau_{p A} \leq 500 \mu \mathrm{s}$. In this case, the normalized ATP of the aperiodic long-term $C$-component of lightning current should be the following numerical values $[3,4]$ : the current amplitude $I_{m C}= \pm(200-800) \quad \mathrm{A} ;$ transferred electric charge $q_{C}= \pm 200 \mathrm{C}$ (with a tolerance of $\pm 20 \%$ ); the duration of the current flow $\tau_{p C}=(0,25-1)$ s. In 2007 , at the Research and Design Institute «Lightning» of the NTU «KPI» a powerful high-voltage generator type УИТОМ-1 artificial lightning current was created [5], which forms on the test technical object ATP pulse current of the lightning discharge on the requirements of the normative documents $[3,4]$. The authors are not known publication of the effects of lightning on the elements of technical installations, made of thin-walled stainless steel.

(C) M.I. Baranov, V.V. Kniaziev, V.I. Kravchenko, S.V. Rudakov 
Therefore, estimates of theoretical and experimental studies of the stability of the level (resistance) of such elements to direct lightning strike them with the current parameters close to the limit, are of practical interest.

1. Problem definition. Consider a flat sample with size in plane of $500 \times 500 \mathrm{~mm}$ from stainless steel $12 \mathrm{X} 18 \mathrm{H} 10 \mathrm{~T}$ of $1 \mathrm{~mm}$ thickness, which is experiencing the outdoors a direct effect of the plasma channel of artificial lightning, which has a cylindrical shape. Let this channel flow pulsed $A$ - and long-term $C$ - current components of lightning, standardized ATPs that correspond to the requirements given in [3, 4]. It is required initially carry an estimate of the results of the electro-thermal effects on the reporting sample of said pulse current component of artificial lightning, and then using a generator-type УИТОМ-1 perform experimental testing electrothermal lighting resistibility prototype to the direct impact it plasma channel artificial lightning.

2. The calculated electrothermal resistance of steel samples to the current of the artificial lightning. We perform the first assessment of the stability of the test specimens of thin steel to act on them pulse current flowing in the channel of the lightning discharge, according to the procedure recommended in [6] by the International Electrotechnical Commission.

2.1. The results of calculations by standardized methodology of evaluate thermal lighting resistibility. The international standard IEC 62305-1 (see Appendix D, formula D.9) shows the analytical relationship, provide an estimate of $V_{0}$ metal object melted due to the effects of lightning current to it, depending on the elapsed with the amount of electricity in the next form [6]:

$$
V_{0}=\frac{U_{a c} \cdot q_{A c}}{d_{0}} \times \frac{1}{C_{w}\left(\Theta_{m}-\Theta_{\mathrm{e}}\right)+C_{s}},
$$

where $V_{0}$ is the volume of melted metal of the object, $\mathrm{m}^{3}$; $U_{a c}$ is the anode or cathode DC voltage drop near the object, $\mathrm{V} ; q_{A c}$ is the the amount of charge carried by the $A$ - or $C$ - component of the lightning current, $\mathrm{C} ; d_{0}$ is the density of the object's material, $\mathrm{kg} / \mathrm{m}^{3} ; C_{w}$ is the heat capacity of the object's material, $\mathrm{J} /\left(\mathrm{kg} \cdot{ }^{\circ} \mathrm{C}\right) ; \Theta_{m}$ is the melting temperature of the object's material, ${ }^{\circ} \mathrm{C} ; \Theta_{e}=\theta_{0}$ is the ambient temperature of the surrounding media, ${ }^{\circ} \mathrm{C}$; $C_{s}$ is the heat of fusion of the object's material, $\mathrm{J} / \mathrm{kg}$.

To assess the size of holes or cavities, which may be formed in this sheet sample of stainless steel with a predetermined thickness $h$ exposed to lightning current, known numerical indicators contact the main physical parameters for stainless steel have been used 12X18H10T shown in Table 1.

After substituting the values of the parameters of the Table 1 in (1) by varying the charge $q_{A c}=q_{c}$ values were obtained cylindrical volume $V_{0}$ of the molten steel, which, when divided into a thickness $h$ of the sheet, gives the corresponding values of the area round the heating zone and the radius $r_{c}$ of penetration holes in a steel specimen shown in Fig. 1.
Table 1

Parameters for the steel 12X18H10T [6-8]

\begin{tabular}{|c|c|c|}
\hline Parameter & Dimensionality & Value \\
\hline$U_{a c}$ & $\mathrm{~V}$ & 10 \\
\hline$d_{0}$ & $\mathrm{~kg} / \mathrm{m}^{3}$ & 7900 \\
\hline$C_{w}$ & $\mathrm{~J} /\left(\mathrm{kg} \cdot{ }^{\circ} \mathrm{C}\right)$ & 462 \\
\hline$\Theta_{m}$ & ${ }^{\circ} \mathrm{C}$ & 1455 \\
\hline$\Theta_{e}$ & ${ }^{\circ} \mathrm{C}$ & 20 \\
\hline$C_{s}$ & $\mathrm{~J} / \mathrm{kg}$ & $84 \cdot 10^{3}$ \\
\hline
\end{tabular}

For a lightning current $C$ - component of duration $\tau_{p C}$ from 2 to $40 \mathrm{~ms}$ charge $q_{c}=q_{A c}=10 \mathrm{C}$ at a current strength is achieved in its channel, ranging from $5 \mathrm{kA}$ to $250 \mathrm{~A}$. When assessing the radius $r_{\mathrm{c}}$ formed holes should be borne in mind that the heat flux is supplied in a steel sample is not a dot, and for the area of a circle of radius $r_{m c}$. Therefore, the molten metal spot radius can not be less than $r_{m c}$. Radius $r_{m c}$ channel of lightning depends on the strength of the current flowing in it and to normal atmospheric conditions is defined as [8]:

$$
r_{m c}=0.11 \cdot 10^{-3}\left(I_{m c}\right)^{0.5} .
$$

where $I_{m C}$ is the maximal value of current for the longterm $C$-component of lighting current in the plate, $\mathrm{A}$.

The results of calculation by (2) of the value of radius $r_{m c}$ of the channel with $C$ - current component are presented in Table 2.

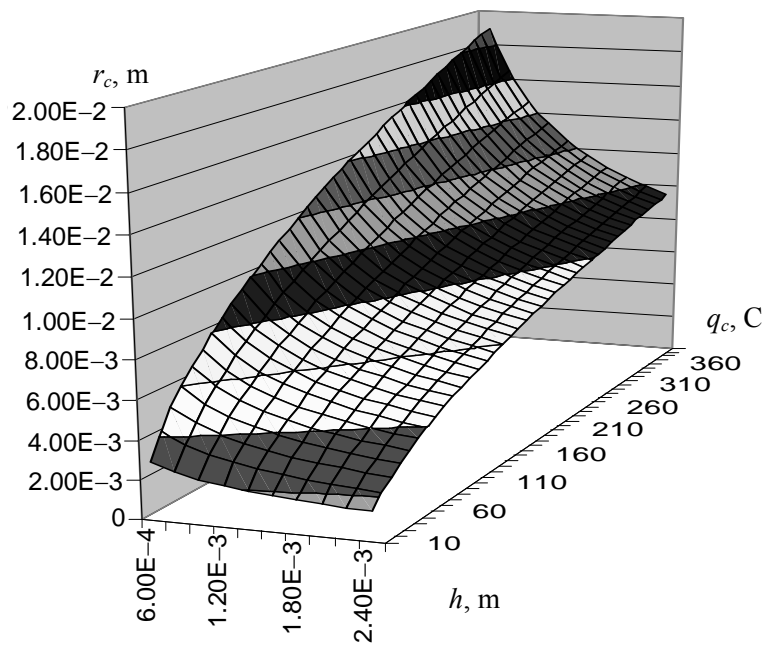

Fig. 1. The dependence of the radius $r_{c}$ of the melting hole formed in the test steel sheet of thickness $h$ via leaked through his material amount of electricity $q_{c}$

Table 2

Values of radius $r_{m c}$ of the channel of lightning depending on the current of $C$-component

\begin{tabular}{|c|c|c|c|c|} 
Current $I_{m C}, \mathrm{~A}$ & 100 & 200 & 400 & 800 \\
\hline Radius $r_{m c}, \mathrm{~mm}$ & 1.10 & 1.56 & 2.20 & 3.11 \\
\hline
\end{tabular}

When the thickness of the steel sheet $h=1 \mathrm{~mm}$ and the elapsed charge $q_{c}=10 \mathrm{C}$ at radius of melting holes therein in accordance with (1) will be approximately equal to $r_{c}=1.64 \mathrm{~mm}$. The same radius, starting from (2), 
has a lightning channel at a current in it $I_{m C}=222 \mathrm{~A}$. We can therefore assume that the action of the steel sheet ( $h=1 \mathrm{~mm}$ ) $C$ - components lasting approximately $40 \mathrm{~ms}$ and the current strength (the average for the time of the action), about 220 A burning of the sheet will occur. For particular values of $C$ - component $q_{c}$ charge current components which have been observed in experiments (see subsection 4 below), the estimated value of the hole diameter $2 r_{c}$ of the selected sample is melted steel $(h=1 \mathrm{~mm})$ at $q_{c}=187 \mathrm{C}$ reaches $20.8 \mathrm{~mm}$; and at $q_{c}=165 \mathrm{C}-18.0 \mathrm{~mm}$. The results of penetration of the steel plate $(h=1 \mathrm{~mm})$ calculated by the method of [6] did not consider the process of heat removal from the sample of the local heating zone of presence of skin effect and merely assume its cylindrical hole burning. Therefore, they are numerically overstated.

2.2. The results of calculations by the method of mathematical modeling based on the applied code. Method of solution of the problem used electrothermal further based on known fundamental analytical solution of the thermal problem for the massive flat metal conductor with instant surface point source disc-shaped heat radius $r_{0}$ [9]. This analytical solution [8] was the first approximation extended to the case of pulsed current at direct lightning strike into a sheet. Between time $0 \leq t \leq t_{0}$ in the area of the circular support band channel has a lightning shape heat source disk radius $r_{0}$ with average heat flux $q_{0}(t)$ applied to the flat outer surface of the metal plate uniform wall. In the cylindrical coordinate system for spatial and temporal changes in the temperature rise $\theta(r, z, t)$ in the material of the wall of a steel sample thickness $h$ in a circular area of effect to it in time air $t$ surface heat flow with the average density $q_{0}(t)$ of the plasma channel lightning current can write the following approximate solution of the unsteady electrothermal problem [8]:

$$
\theta(r, z, t)=\frac{1}{\left(\pi \lambda_{0} c_{0}\right)^{1 / 2}} \int_{0}^{t_{0}} r_{0}(\tau) q_{0}(\tau) F(r, z, t-\tau) d \tau,
$$

where $\theta(r, z, t)=\left(\theta_{t}-\theta_{0}\right)$ is the temperature rise of the wall material of the metal sample; $\theta_{t}$ is the current and timevarying temperature of the flat wall of the sample material; $\theta_{0}$ is the ambient temperature of the air around the wall; $r$ is the radial coordinate directed from the axis of the current channel of lightning along the wall of a flat sample; $z$ is the longitudinal coordinate directed from the lightning current hearth heat exposure inside the center of the flat walls of the sample; $q_{0}(\tau)$ is the average density acting on the wall surface steel sample heat flow caused by lightning plasma channel;

$$
\begin{aligned}
& F(r, z, t-\tau)=\exp \left[-z^{2} c_{0} / 4 \lambda_{0}(t-\tau)\right] \times \\
& \times(t-\tau)^{-1 / 2} \int_{0}^{\infty} \exp \left[-\lambda_{0}(t-\tau) \mathrm{v}^{2} / c_{0}\right] J_{0}(v r) J_{1}\left(v r_{0}\right) d v ;
\end{aligned}
$$

$\tau, v$ are the auxiliary variables; $r_{0}(\tau)$ is the current value of the lightning current channel radius; $t$ is the current time; $t_{0}$ is the duration of the pulsed $A$ - and long-term $C$ components of the lighting current; $J_{0}, J_{1}$ are the respectively the Bessel functions of zero and first order; $\lambda_{0}, c_{0}$ are the respectively the thermal conductivity and specific heat capacity of the wall of the volume of flat steel material sample taken for the solved problem constants.

Described briefly the mathematical model has been implemented as an application program [10], which allows the calculation of the consequences of thermal effects on the pulsed $A$ - and long-term $C$ - components of lightning current. Here joint consistent effect on steel samples of said lightning current component is not considered. The results of the approximate numerical calculations on the program [10] the thermal action of only one pulse $A$ - component lightning current on a steel sample $(h=1 \mathrm{~mm})$ are presented in Table 3 .

Table 3

Results of assessment of the thermal action of A- component on the steel sample [10]

\begin{tabular}{|c|c|c|c|c|}
\hline $\begin{array}{c}I_{m A}, \\
\text { кA }\end{array}$ & $\begin{array}{c}t_{m A}, \\
\mu \mathrm{s}\end{array}$ & $\begin{array}{c}\tau_{p A}, \\
\mu \mathrm{s}\end{array}$ & $\begin{array}{c}\text { Melting depth } h_{m A}, \\
\mathrm{~mm}\end{array}$ & $\begin{array}{c}\text { Melting radius } r_{m A}, \\
\mathrm{~mm}\end{array}$ \\
\hline 192 & 34 & 500 & 0.04 & 31.6 \\
\hline
\end{tabular}

In addition to the above, we note that we are considering the case of the radius $\mathrm{r} 0 \mathrm{~A}$ channel lightning pulse $A$ - component according to its current by the Braginsky formula as follows [8]:

$$
r_{0 A}=0.093\left(I_{m A}\right)^{1 / 3}\left(t_{m A}\right)^{0.5} .
$$

When $I_{m A}=192 \mathrm{kA}$ and $t_{m A}=34 \mu$ radius $r_{0 A}$ of the lightning channel, calculated at (4) is equal to $31.3 \mathrm{~mm}$. It is evident that this numerical value of radius $r_{0 A}=31.3 \mathrm{~mm}$ is consistent with the radius of $r_{m A}=31.6 \mathrm{~mm}$ surface melting steel sample zone, caused by the action of pulse $A$ - component to it. As a result of pulsed $A$ - component with a current $I_{m A}=192 \mathrm{kA}$, through penetration of the sheet is not observed. In accordance with Table A.3 of the Standard [6] with a current probability of lightning more $200 \mathrm{kA}$ is not more than $0.01(1 \%)$. Therefore, thermal effect alone activities $A$ - lightning impulse current component of the steel sheet with a thickness $h=1 \mathrm{~mm}$ and more can be ignored in terms of occurrence of it therein through hole.

The results of assessment on the basis of (2) and (3) a steel plate $(h=1 \mathrm{~mm})$ on the thermal action on its outer surface of long-term lightning current $C$ - component are shown below in Table 4 .

It should be noted, that the physics of the process in real lightning current sheet is more complicated than in the above calculation model. An important factor here is the consistent flow of the $A$ - and $C$ - current components. As a result, the wall is done preheating object $A$ component of the current. Therefore, obtained by [10], the results underestimate the value of the radius of the hole in the steel sheet for the received version of their action. We 
can assume that the actual size of the hole in a sheet of two-component impact of natural lightning are between the values of the diameters calculated according to the methods discussed above.

Table 4

Results of assessment of the thermal action of long-term $C$ - lightning current component on the flat steel sample of thickness $h=1 \mathrm{~mm}$ [10]

\begin{tabular}{|c|c|c|c|c|}
\hline $\begin{array}{c}q_{C}, \\
\mathrm{C}\end{array}$ & $\begin{array}{c}I_{m C}, \\
\mathrm{~A}\end{array}$ & $\begin{array}{c}T_{C}=T_{\text {long }}=t_{0}, \\
\mathrm{~ms}\end{array}$ & $\begin{array}{c}\text { Diameter } 2 r_{c} \text { of the } \\
\text { melted hole, } \mathrm{mm}\end{array}$ & $\begin{array}{c}\text { Average } \\
\text { current, } \mathrm{A}\end{array}$ \\
\hline $10^{*)}$ & 500 & 40 & 2.72 & 250 \\
\hline $20^{*)}$ & 1000 & 40 & 4.06 & 500 \\
\hline $40^{1)}$ & 800 & 100 & 4.96 & 400 \\
\hline 125 & 500 & 500 & 6.40 & 250 \\
\hline 200 & 800 & 500 & 7.72 & 400 \\
\hline $350^{2)}$ & 1400 & 500 & 9.68 & 700 \\
\hline
\end{tabular}

Note.

*) The probability of exceeding the tolerable in the plasma channel lightning storm magnitude charge $q_{C}$ of $10 \mathrm{C}$ and $20 \mathrm{C}$, respectively, as determined by $50 \%$ and $20 \%$ ([6], see Fig. A.5);

1) Excess of $q_{C}$ amount of charge over $40 \mathrm{C}$ transported downward lightning negative polarity, has a probability of less than $5 \%$ (see [6], Table A.1);

2) Excess of the value of the lightning charge $q_{C}$ over $350 \mathrm{C}$ transported by the lightning of positive polarity, has a probability of less than $5 \%$ (see [6], Table A.1).

3. The test circuit and the electrical parameters of high-power high-voltage generators of PCG- $\boldsymbol{A}$ and PCG-C. Fig. 2 is a schematic diagram of the type of generator УИТОМ-1 used in the experimental studies on electrothermal lighting resistibility of test specimens (TS) of the selected steel roofing technical facilities. From this scheme it is clear that the structure of two separate and parallel operating one electrical load type УИТОМ-1 generator included TS of pulse current generator (PCG), one of which PCG- $A$ simulates pulse $A$ - component of an artificial lightning current and other PCG-C - long-term $C$ - component of artificial lightning current. We point out that their own electrical parameters of the discharge circuit generator HIT-A up [5]: resistance $R_{A} \approx 0.057 \Omega$; inductance $L_{A} \approx 2,5 \mu \mathrm{H}$; capacity $C_{A} \approx 333 \mu \mathrm{F}$. Own the electrical parameters of the discharge circuit generator PCG-C were equal to [5]: resistance $R_{C} \approx 4.74 \Omega$; inductance $L_{C} \approx 11.43 \mathrm{mH}$; capacitance $C_{C} \approx 45.36 \mathrm{mF}$. Generator PCG- $A$ was compiled on the basis of 111 parallel-connected high-voltage pulse capacitors such as ИК-50-3 (rated voltage of $\pm 50 \mathrm{kV}$; nominal capacity 3 $\mu \mathrm{F}$ ) and PCG-C generator - based on 324 parallel connected high-voltage pulse capacitors ИМ2-5-140 (nominal voltage $\pm 5 \mathrm{kV}$; nominal capacity $140 \mu \mathrm{F}$ ) [5, 11]. The discharge circuit generator PCG- $A$ threeelectrode mounted air switch $F_{1}$ with massive steel electrodes, and the discharge circuit PCG- $C$ generator air-electrode switch $F_{2}$ with graphite electrodes.

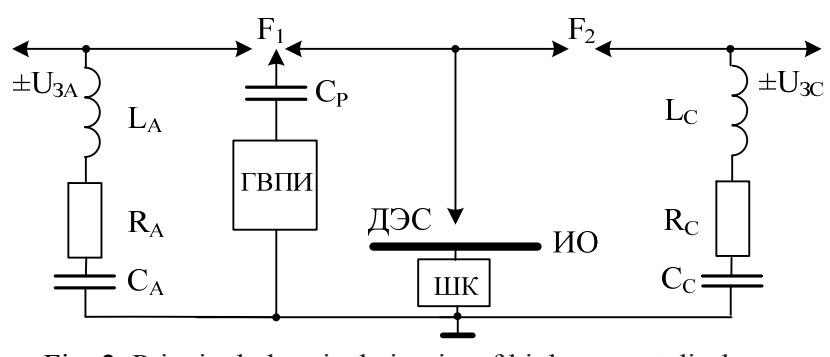

Fig. 2. Principal electrical circuits of high-current discharge circuits of generators PCG- $A$ and PSG- $C$ to form a roof in steel sample pulse $A$ - and long-term $C$ - artificial lightning current components (ГВПИ - generator of high-voltage igniting microsecond pulse amplitude voltage of $\pm 100 \mathrm{kV} ; F_{1}, F_{2}-$ respectively, three and two-electrode spark high-voltage overhead switches PCG- $A$ and PSG- $C ; C_{p} \approx 180 \mathrm{pF}$ - luggage capacity on the pulse voltage up to $\pm 120 \mathrm{kV}$ in the circuit of ГВПИ controlling the actuation of the spark switches $F_{1}$ and $F_{2}$; ДЭС - two-electrode system; ИО - roof test specimen; ШК shunt coaxial type ШК-300 for measurement of artificial lightning impulse current amplitude from \pm 10 to $\pm 300 \mathrm{~A} \mathrm{kA}$; $\pm U_{3 A}, \pm U_{3 C}-$ charge voltages respectively of PCG- $A$ and PSG- $C ; L_{A}$ and $L_{C}, R_{A}$ and $R_{C}, C_{A}$ and $C_{C}$ - respectively own inductances, active resistances and capacitances of discharged circuits of PCG- $A$ and PCG-C) [8]

High-voltage switches $F_{1}$ and $F_{2}$ are high voltage products of own production [12]. Flat steel sample according to Fig. 2 firmly fixed on the desktop, a powerful generator of УИТОМ-1 between the massive aluminum electrodes that are connected to the bit generator circuits PCG- $A$ and PSG- $C$. In the test circuit as shown in Fig. 2 for playback on plasma channel TS artificial lightning using air two-electrode system (TES), provided with a thin electrically exploding wire (EEW). As an EEW in accordance with [3, 4], a copper wire with a diameter of $0.2 \mathrm{~mm}$ and a length $l_{e}=(37-50) \mathrm{mm}$. Fig. 3 shows in enlarged form the TES of the generator desktop УИТОМ-1. The air gap between the top $h_{a}$ a massive cylindrical electrode TES and massive flat bottom electrode - TS could range from 27 to $14 \mathrm{~mm}$. Air gap $h_{a}$ in TES between EEW and TS remained unchanged and equal to about $1 \mathrm{~mm}$.

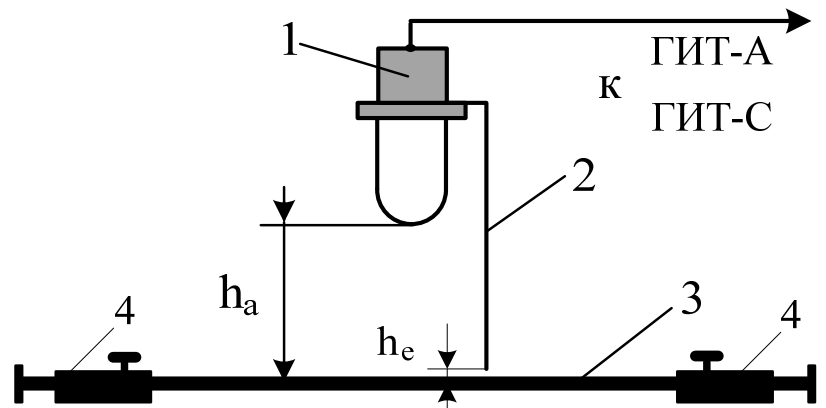

Fig. 3. Enlarged schematic representation of TES used in highcurrent discharge circuit generators PCG- $A$ and PSG- $C$ in the preparation of flat steel TS at pulse $A$ - and long-term $C$ - current component of an artificial lightning ( 1 - upper massive cylindrical steel electrode, 2 - thin copper EEW; 3 - lower the massive flat steel electrode (TS); 4 - solid aluminum electrodes are designed to secure the TS; $h_{a}$ - the length of the air gap in the TES; $h_{e}$ - the length of the air gap between the lower edge of the circular copper EEW and the outer flat surface of the TS) [8] 
Fig. 4 is a perspective view of used TES.

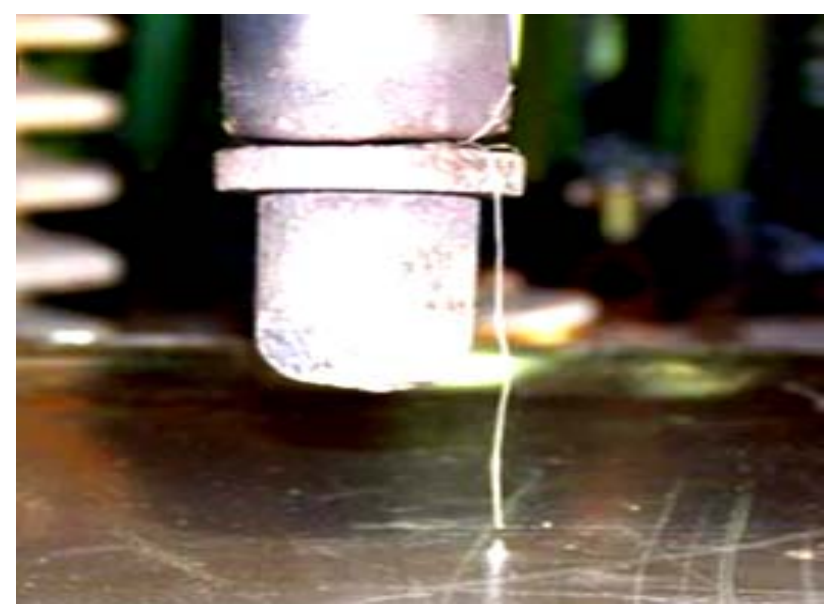

Fig. 4. General view of the TES with copper EEW desktop of generators PCG- $A$ and PSG- $C$ when tested in their discharge circuits TS thin steel roof on electrothermal resistance to direct impact on them of pulse $A$ - and long-term $C$ - artificial lightning current components with a normalized according to [3, 4] ATP

$$
\left(l_{e}=37-50 \mathrm{~mm}\right)[8]
$$

Charge voltages of high-voltage capacitors generators PCG- $A$ and PSG- $C$ to perform the planned experiments selected negative polarity, and the modules, respectively, their levels do not exceed $U_{3 A} \leq 25 \mathrm{kV}$ and $U_{3 C} \leq 4.2 \mathrm{kV}$. Selecting the polarity of the charging voltages $U_{3 A}$ and $U_{3 C}$ determines the need for physical modeling of the most severe in terms of electrothermal conditions described in the TES and, respectively, in the area round the binding of a high cylindrical plasma channel with artificial lightning current on the outer surface of the flat steel roof TS technical facilities. To prevent mechanical damage to the capacitor banks generators PCG- $A$ and PSG- $C$ and provide the required safety conditions and safety for maintenance powerful generator type УИТОМ-1 personnel in the emergency mode of his work (for example, in electrical breakdown of insulation of at least one of the 435 these capacitors in their charge or discharge) all high-voltage outputs are used capacitors generators PCG- $A$ and PSG- $C$ protective resistance were installed, made from high-voltage constant bulk graphite-ceramic resistors type TBO-60 for $\mathrm{DC}$ voltage $\pm 25 \mathrm{kV}[5,13]$. Moreover, in the terminal of the capacitor-type ИК-50-3 were installed protective resistors type TBO 60-24 $\Omega$ (rigid assembly of four parallel connected resistors), and ИМ2-5-140 type capacitor terminals - one protective resistor type TBO60-100 $\Omega$. Parallel operation of generators PCG- $A$ and PSG- $C$ on steel roof of the TS according to the diagram in Fig. 1 simultaneous actuation of high-voltage threeelectrode-managed air switch $F_{1}$ with massive hemispherical steel main electrodes at the rated voltage of $\pm 50 \mathrm{kV}$ [12] and the high-voltage two-electrode air switch $F_{2}$ with massive rectangular graphite electrodes containing a flat working surface, a rated voltage of $\pm 10 \mathrm{kV}$ [12]. In turn, the synchronous operation of switches $F_{1}$ and $F_{2}$ performed by feeding through the separating capacity $C_{p}$ to switch $F_{1}$ average spherical steel electrode set fire by a generator of high-voltage pulses (GHVP) of microsecond duration voltage pulse amplitude to $\pm 100 \mathrm{kV}[5,12]$. In the breakdown by GHVP one of the two air gaps switch $F_{1}$ and its subsequent activation occurs surge voltage to a TES with TS leads to virtually simultaneous with it and triggering the switch $F_{2}$. After tripping switches $F_{1}$ and $F_{2}$ due to discharge pre-charged high-voltage capacitors generators PCG- $A$ and PSG- $C$ through TS of steel roofing technical facilities begin to flow simulated lightning current pulses required by $[3,4]$ ATP. It should be noted that the nominal value of the stored electrical energy in the power generators PCG- $A$ and PSG- $C$ are respectively 416 and $567 \mathrm{~kJ}[5,8,13]$.

Measuring ATP of pulsed $A$ - and long-term $C$ artificial lightning current component in the identity of the roof steel was carried out with the help of attorneys metrological service measuring coaxial shunt type ШК300 [14], has for these currents, respectively, conversion factors $K_{A} \approx 10417 \mathrm{~A} / \mathrm{V}$ and $K_{C} \approx 5219 \mathrm{~A} / \mathrm{V}$ and digital storage oscilloscope Tektronix TDS 1012 type.

4. Results of tests of the roof steel samples for resistance to pulsed $A$ - and long-term $C$ - artificial lightning current component. Fig. 5 shows a general view of the desktop with powerful TES generator УИТОМ-1 and is rigidly fixed to it a flat roof TS steel thickness $h=1 \mathrm{~mm}$ in the grooves of massive aluminum electrodes that are included in the high-current discharge circuit of high-voltage generators of PCG- $A$ and PSG- $C$.

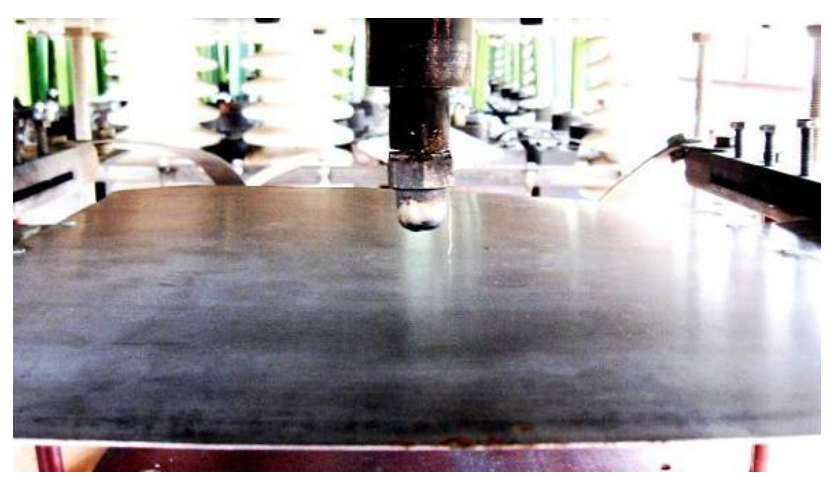

Fig. 5. External view of Ts of steel roof fixed in TES with EEW desktop УИТОМ-1 type generator, to direct exposure to high-voltage generators of PCG- $A$ and PSG- $C$ of pulsed $A$ - and long-term $C$ - artificial lightning current component $\left(h_{a}=27 \mathrm{~mm} ; l_{e}=50 \mathrm{~mm}\right)$

The following two types of experiments to determine the electrothermal lighting resistibility identical TS steel roofs have been received for the same values of charging voltage in the PCG- $A$ and PSG- $C$ ( $U_{3 A}=-25 \mathrm{kV}$; $U_{3 C}=-4.2 \mathrm{kV}$ ), the air gap $h_{e} \approx 1 \mathrm{~mm}$ and two values of the air gap $h_{a}$, equal to 27 and $14 \mathrm{~mm}$.

4.1. Results of experiments at $\boldsymbol{h}_{\boldsymbol{a}}=\mathbf{2 7} \mathbf{~ m m}$. Fig. 6 shows the waveform of pulsed $A$ - component of artificial 
lightning current flowing in the identity of the roof steel technical facilities.

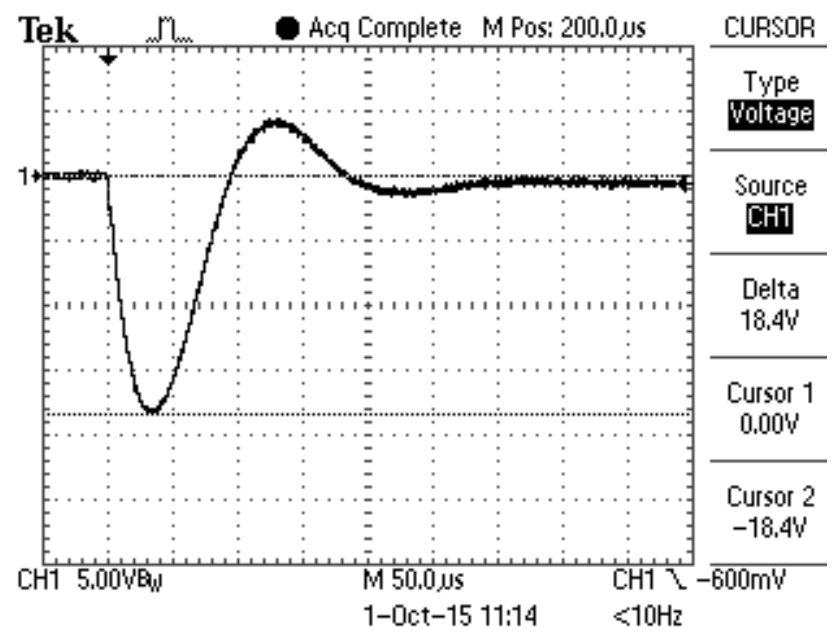

Fig. 6. Waveform of pulsed $A$ - component of artificial lightning current acting on the TS of the roof

From decoding of the waveform it follows that for this case the amplitude of the first pulse $A$-component of artificial lightning current TS steel roof was $I_{1 m A} \approx-192 \mathrm{kA}$. This amplitude decaying exponentially oscillating current component corresponds to the time $t_{m A}$, equal to $34 \mu \mathrm{s}$. The duration of the first half-wave $\tau_{1 A}$ current in this case was about $94 \mu \mathrm{s}$, and the total duration of the current components $\tau_{p A}$ simulated lightning - about $500 \mu$ s. Fig. 7 is a waveform of $C$ - aperiodic long-term artificial lightning current amplitude components $I_{m C} \approx-804 \mathrm{~A}$, flowing in the id stainless steel roof $(h=1$ $\mathrm{mm})$. It can be seen that the duration of this component $\tau_{C}$ lightning surge current at $0.5 \cdot I_{m C}$ was equal to about 160 $\mathrm{ms}$, and its complete length $\tau_{p C}-$ about 0.516 s. $t_{m C}$ time corresponding $I_{m C}$ amplitude equals to $9 \mathrm{~ms}$.

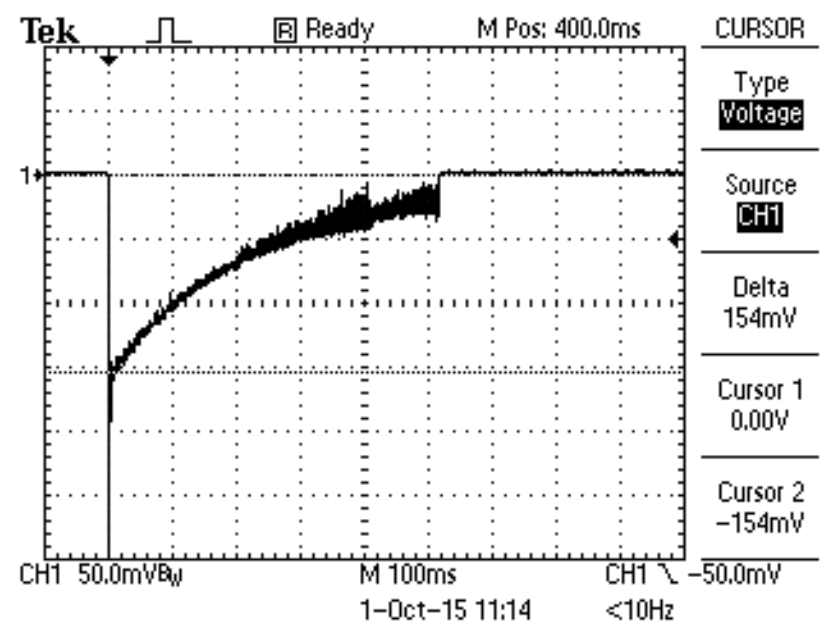

Fig. 7. Waveform of long-term $C$ - component of artificial lightning current acting on the TS of the roof

According to Fig. 6 on the curve of the long-term $C$ - components of artificial lightning current, especially in the final stages of its course, clearly visible multiple superimposed oscillations due to combustion instability of TS pulse arc of the roof in the air gap length $h_{a}=27 \mathrm{~mm}$. At the current time $t$, equal to $\tau_{p C} \approx 0.516 \mathrm{~s}$, given the instability of the arc leads to the edge of the plasma channel and an end to the long-term $C$-component of the current in the tested TS of the steel roof. Decoding the waveform in Fig. 6 shows that over time the amount of electricity from $\tau_{p C} \approx 0.516 \mathrm{~s}$, elapsed in the discharge circuit of the generator PSG- $C$ through the TS of the roof, was in this case the absolute value of about $178 \mathrm{C}$. This charge corresponds to the average value of current used in current components in the TS equal $i_{C C} \approx q_{C} \tau_{p C} \approx-345 \mathrm{~A}$.

Figures 8 and 9 show the outer appearances and back surfaces of the TS steel roof after co-exposure to the pulsed $A$ - and long-term $C$ - artificial lightning current component with the ATP, the relevant data waveforms in Fig. 6 and 7. It can be seen that the penetration through the wall of the roof TS stainless steel thickness $h=1 \mathrm{~mm}$, in this case $\left(h_{a}=27 \mathrm{~mm}\right)$ has not occurred. Rounded binding zone on the outer surface of the steel roof TS of pulsed $A$ - component of simulated lightning current was the largest dimension of up to $60 \mathrm{~mm}$. The depth of the crater formed in this area does not exceed $50 \mu \mathrm{m}$. The circular zone of long-term $C$ - binding prolonged artificial lightning current local melting of the components occurred TS steel wall material of the roof, having a melting point of about $1455{ }^{\circ} \mathrm{C}[7,15]$. The diameter of the melting zone as shown in Fig. 8 and 9 does not exceed $23 \mathrm{~mm}$. On the back surface of the steel roof of the TS clearly manifested «discoloration» the action of its material high temperature pulsed Joule heating.

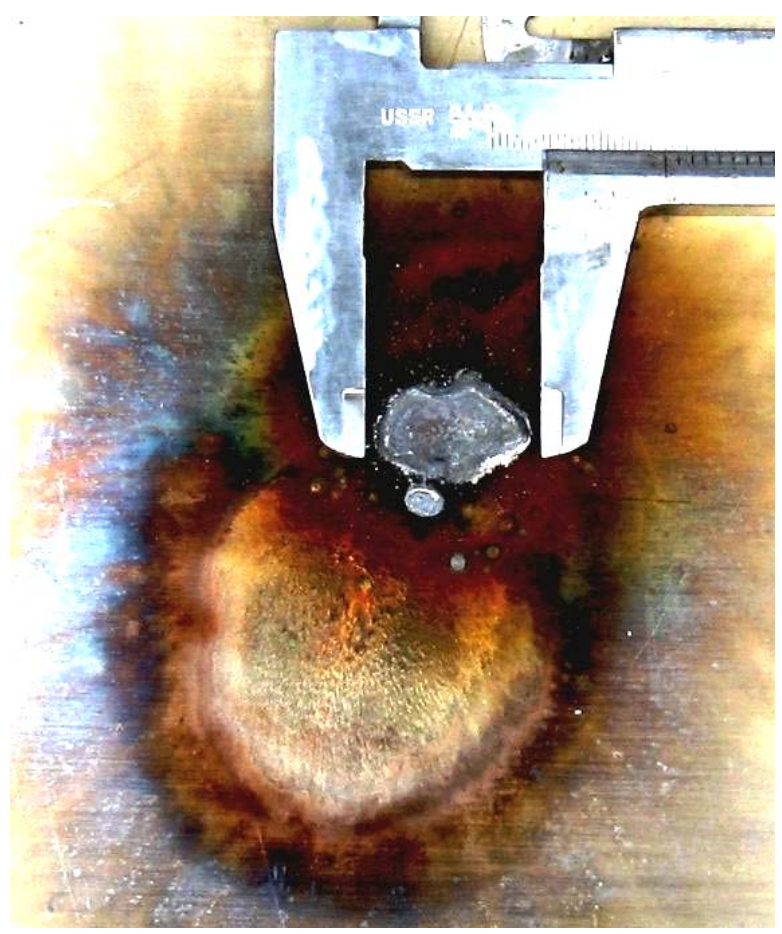

Fig. 8. General view of the outer surface of the steel roof TS circular hearth direct exposure to the pulsed $A$ - and long-term $C$ - artificial lightning current component with a normalized according to the requirements $[3,4]$ ATP 


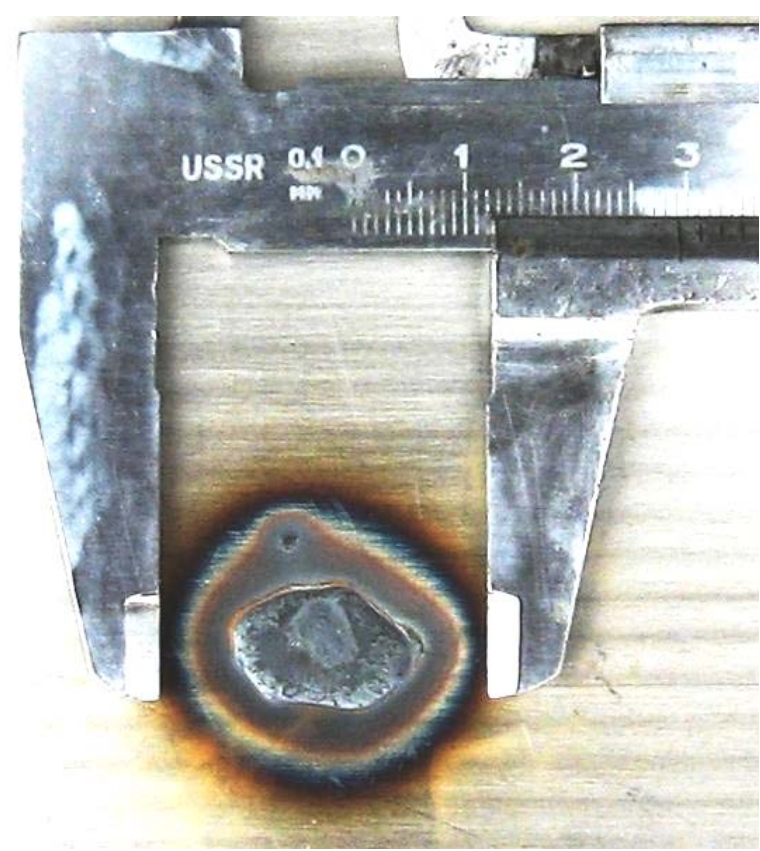

Fig. 9. General view on the rear surface of the TS steel roof rounded hearth direct exposure to the pulsed $A$ - and long-term $C$ - artificial lightning current component with a normalized according to the requirements $[3,4]$ ATP

4.2. Results of experiments at $\boldsymbol{h}_{\boldsymbol{a}}=\mathbf{1 4} \mathrm{mm}$. Figures 10 and 11 show waveforms respectively for pulsed $A$ - and long-term $C$ - prolonged artificial lightning current components obtained with respect to the test steel roof of the TS electrothermal lighting resistibility decreases in TES value $h_{a}$ to $14 \mathrm{~mm}$. ATP of the pulsed components of the simulated lightning current at the same time fully consistent with the ATP this current component of the lightning discharge, shown in Fig. 6. With regard to ATP of the long-term $C$ - component of the current simulated lightning, in this case $\left(h_{a}=14 \mathrm{~mm} ; l_{e}=37 \mathrm{~mm}\right)$ were changed only their three parameters: total duration $i_{C}$ current flow decreased to $\tau_{p c} \approx 0.448 \mathrm{~s}$; elapsed charge has decreased to a value of $q_{C} \approx 165 \mathrm{C}$; average current increased to the level of $i_{C C} \approx-367 \mathrm{~A}$. Despite these changes in the long-term ATP of the long-term $C$ components of artificial lightning current, in this case occurred keyhole TS roof wall stainless steel with thickness $h=1 \mathrm{~mm}$. Diameter $2 r_{c}$ penetration holes in TS was $12 \mathrm{~mm}$ (Fig. 12).

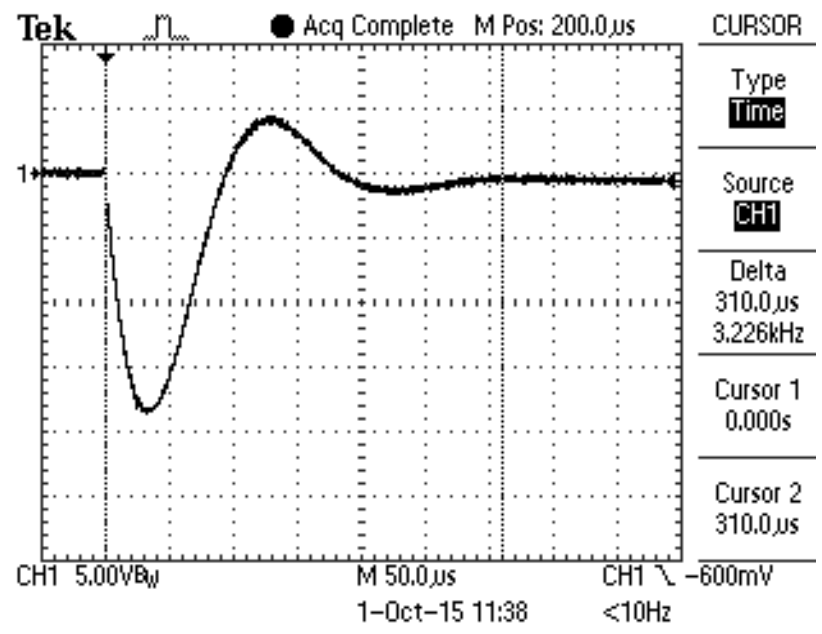

Fig. 10. Waveform of the pulsed $A$ - component of artificial lightning current acting in high-current discharge circuit highvoltage generator PCG- $A$ on flat steel roof of thickness of $h=1 \mathrm{~mm}\left(I_{1 m A} \approx-192 \mathrm{kA} ; t_{m A} \approx 34 \mu \mathrm{s} ; \tau_{p A} \approx 500 \mu \mathrm{s} ; J_{A} \approx 1.9 \cdot 10^{6} \mathrm{~A}^{2} \cdot \mathrm{s}\right)$

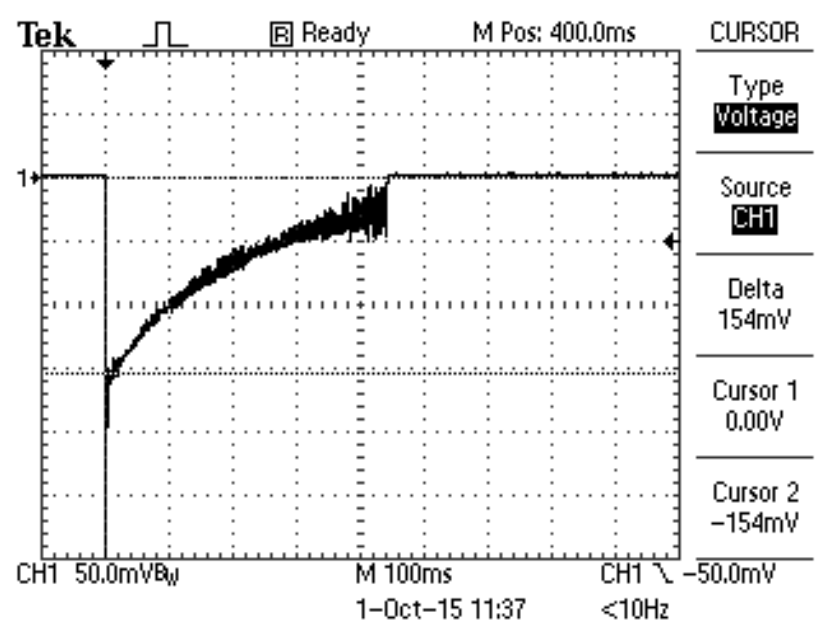

Fig. 11. Waveform of the long-term $C$ - component of artificial lightning current acting on the flat roof of the TS steel of thickness of $h=1 \mathrm{~mm}\left(I_{m C} \approx-804 \mathrm{~A} ; t_{m} \approx 9 \mathrm{~ms} ; \tau_{C} \approx 160 \mathrm{~ms}\right.$; $\left.\tau_{p C} \approx 0.448 \mathrm{~s} ; q_{C} \approx-165 \mathrm{C} ; i_{C C} \approx-367 \mathrm{~A}\right)$

Obtained when $h_{a}=14 \mathrm{~mm}$ experimental results concerning the keyhole simulated lightning current of the test thin-walled sample steel roof technical facilities, it can be explained by the fact that a decrease in the length of the air gap $h_{a}$ in TES (respectively, and the length $l_{e}$ for EEW) desktop type used generator УИТОМ-1 comes stabilization zones binding on the outer surface of the TS steel roof of plasma channels for long-term $C$ - and pulsed $A$ - artificial lightning current component. In addition, the decrease in the value $h_{a}$ prevents branching (division) in the air cylinder configuration corresponding plasma channels for high-voltage electrical pulse and arcs (trace smelting from such channel separation for simulated $C$ current components of lightning just present in Fig. 8 and 9) which also contributes to the local concentration of heat energy generated in the material studied stainless steel roofing samples. 


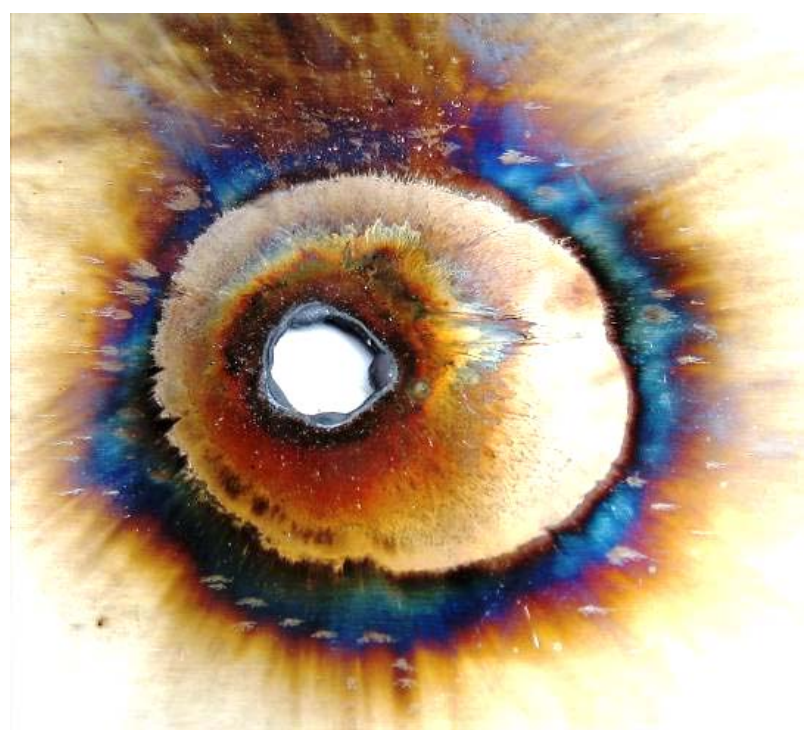

Fig. 12. External view of the area with a diameter of about $12 \mathrm{~mm}$ of penetration through the flat wall TS steel roof ( $h=1 \mathrm{~mm} ; h_{a}=14 \mathrm{~mm}$ ) by a direct action on long-term $C$ - component of the current artificial lightning and rounded zone diameters up to $58 \mathrm{~mm}$ in its surface melting from direct action on TS of pulsed $A$ - components of with standardized requirements for $[3,4]$ ATP

In favor of this physical explanation of penetration through the wall of the test thin-walled steel roof TS used by us pulse currents with a decrease in the length of the air gap in the TES $h_{a}$ (even with a decrease in leaked through the TS of the electric charge for a long-term $C$ artificial lightning current component from 178 to $165 \mathrm{C}$ ) show results followed by a series of experiments carried out on a powerful generator type УИТОМ-1 study at ТS $h_{a}=14 \mathrm{~mm}$. Figures 13 and 14 show the corresponding waveform for use in this case pulse current component of artificial lightning. If the curve for the pulse current component A simulated lightning in the latter case, repeats similar curves for this current component of artificial lightning, shown in Fig. 6 and 10, the curve for long-term $C$ - lightning current component are significantly different from those of the current curves shown in Fig. 7 and 11. These differences mainly relate to more stable combustion over TES in high TS $i_{C}$ pulsed arc with a current in the air gap length $h_{a}=14 \mathrm{~mm}$. One of the signs of the process flow of the arc is the virtual absence of the curve aperiodic current $i_{C}$ imposed considerable amplitude fluctuations (see Fig. 14). The consequence of this electromagnetic process is increased the total duration $\tau_{p C}$ flow through pulse current TS steel roof $i_{C}$, reaching the numerical value of $0.736 \mathrm{~s}$. This implies also an increased amount of electricity $q_{C} \approx-187 \mathrm{C}$, elapsed through a rounded zone of the plasma channel binding long-term $C$ - component of artificial lightning current on the outer surface of the TS.

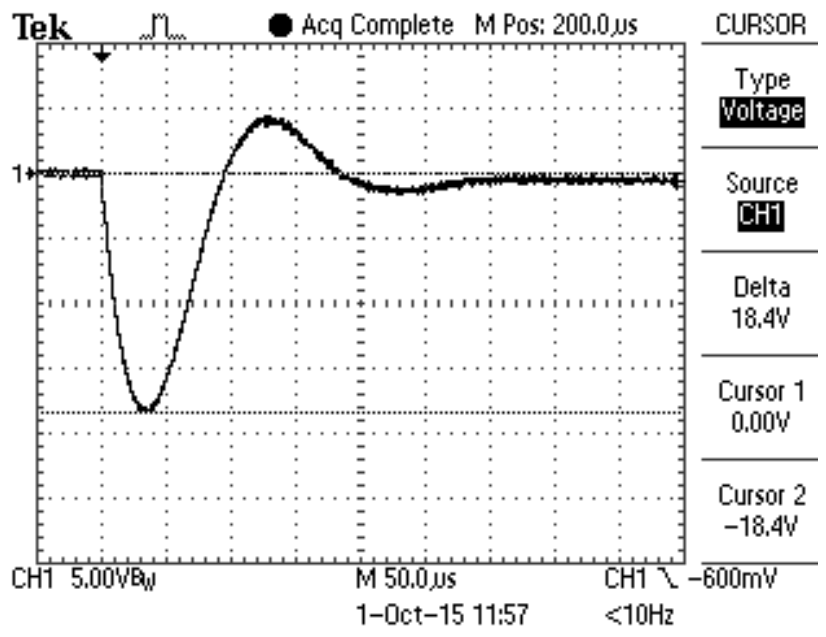

Fig. 13. Waveform of the pulsed $A$ - component of simulated lightning current acting in high-current discharge circuit PCG- $A$ high-voltage generator on a flat thin-walled steel roof IO of thickness of $h=1 \mathrm{~mm}\left(I_{1 m A} \approx-192 \mathrm{kA} ; t_{m A} \approx 34 \mu \mathrm{s} ; \tau_{p A} \approx 500 \mu \mathrm{s}\right.$; $\left.J_{A} \approx 1.9 \cdot 10^{6} \mathrm{~A}^{2} \cdot \mathrm{s}\right)$

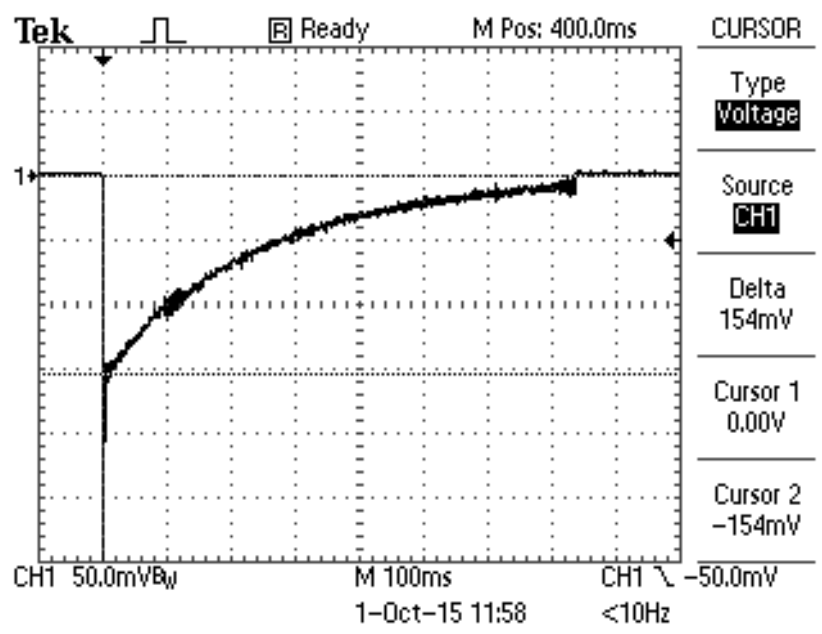

Fig. 14. Waveform of the long-term $C$ - component of simulated lightning current acting in high-current discharge circuit PCG-C high-voltage generator on a flat thin-walled steel roof IO of thickness of $h=1 \mathrm{~mm}\left(I_{m C} \approx-804 \mathrm{~A} ; t_{m C} \approx 9 \mathrm{~ms} ; \tau_{C} \approx 160 \mathrm{~ms}\right.$; $\left.\tau_{p C} \approx 0.736 \mathrm{~s} ; q_{C} \approx-187 \mathrm{C} ; i_{C C} \approx-254 \mathrm{~A}\right)$

Fig. 15 shows the appearance of the direct results of the joint impact on the flat thin-walled $\left(h=1 \mathrm{~mm} ; h_{a}=14\right.$ $\mathrm{mm})$ of the TS roof stainless steel pulsed $A$ - and longterm $C$ - artificial lightning current component normalized by $[3,4]$, the ATP which led to keyhole steel wall TS. $2 r_{m A}$ diameter of the surface (to a depth of no more than $50 \mu \mathrm{m})$ electrothermal exposure chamber on the outer surface of the flat roof on steel TS from pulsed $A$ - simulated lightning current components made with up to $59 \mathrm{~mm}$. The diameter of the holes in the area of penetration through the wall of the test sample from the roof of the electrothermal effect on her long-term component of the current long-term $C$ - simulated lightning was $15 \mathrm{~mm}$. 


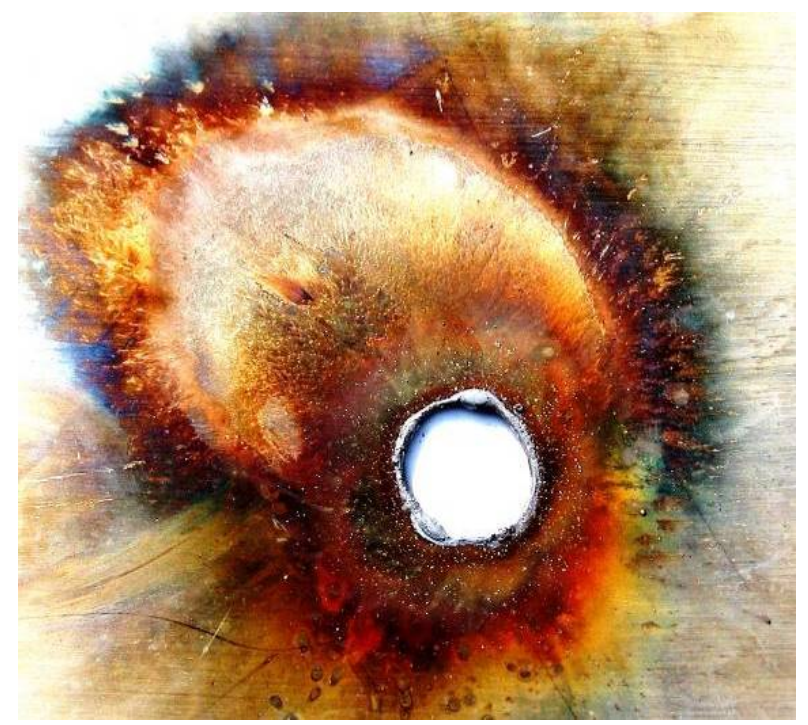

Fig. 15. External view of rounded zones of thermal influence on the flat roof of the TS steel of pulsed $A$ - and long-term $C$ artificial lightning current components with standardized requirements for $[3,4]$ ATP accompanied keyhole TS wall $(h=1$ $\mathrm{mm} ; h_{a}=14 \mathrm{~mm}$ )

\section{Comparison of the results of calculation} estimations and performed experiments. This comparison is conducted for the case of a direct action on experimental walled $(h=1 \mathrm{~mm})$, the samples of stainless steel 12X18H10T $C$ - current component shown in Table 5 (the experiments were performed at the air gap length in TES $h_{a}=14 \mathrm{~mm}$ ).

Comparative data for the results of the executed calculations and experiments for evaluating thermal lighting resistibility of steel samples

\begin{tabular}{|c|c|c|c|}
\hline \multirow{2}{*}{$\begin{array}{c}\text { Значение } \\
\text { заряда } q_{c}, \text { C }\end{array}$} & \multicolumn{3}{|c|}{$\begin{array}{c}\text { Diameter of the melted hole in the steel sample } \\
\text { wall }(h=1 \mathrm{~mm}), \mathrm{mm}\end{array}$} \\
\cline { 2 - 4 } & Experiment & $\begin{array}{c}\text { By formula } \\
(1)\end{array}$ & $\begin{array}{c}\text { Numerical method } \\
{[10]}\end{array}$ \\
\hline 165 & 12.0 & 18.0 & 7.1 \\
\hline 187 & 15.0 & 20.8 & 7.7 \\
\hline
\end{tabular}

From Table 5 it follows that the calculated results of the evaluation electrothermal lighting resistibility of steel specimens ( $h=1 \mathrm{~mm}$ ) using (1) satisfactory (with an accuracy of up to $28 \%$ ) agree with the results of the experiments.

Conclusions.

1. The results obtained at the Research and Design Institute «Lightning» of the NTU «KPI» computational and experimental evaluation studies electrothermal resistance experienced flat sample size in terms $500 \times 500$ $\mathrm{mm}$ stainless steel $1 \mathrm{~mm}$ thick to the direct impact on them in the air of pulsed $A$ - and long-term $C$ - artificial lightning current components with standardized ATPs according to the applicable requirements of the US regulations SAE ARP 5412 and SAE ARP 5416 indicate that we investigated thin-walled steel samples can be exposed keyhole. The diameter of the through-hole penetration in the investigated samples of steel round anchor zone on the outer surface of the plasma channel of long-term $C$ - components of simulated in the laboratory lightning current can reach $15 \mathrm{~mm}$.

2. A significant influence on the results of the electrothermal effects of artificial lightning plasma channels with $A$ - and $C$ - components of the pulse current at the steel studied experienced technical facilities provide examples of electrical processes of binding the corresponding plasma channels on their outer surface and burning them on a high-voltage pulse of the arc in the air gap TES used in the experiments, a powerful high-voltage generator type УИТОМ-1 artificial lightning current.

3. To prevent possible flashpoint of flammable liquids and materials, placed under the bottom of the thin-walled steel liner with these characteristics, is striking in the open air directly blows high-lightning, it requires the development of specific technical measures that increase the fire safety of such technical facilities to act on them large pulsed lightning currents.

\section{REFERENCES}

1. Yuman M.A. Molniya [Lightning]. Moscow, Mir Publ., 1972. 327 p. (Rus).

2. Kravchenko V.I. Molniya. Elektromahnitny faktory $i$ porazhayushchie vozdeystviya na tekhnycheskie sredstva [Lightning. Electromagnetic factors and their impact on the striking technical objects]. Kharkov, NTMT Publ., 2010. 292 p. (Rus).

3. SAE ARP 5412: 2013. Aircraft Lightning Environment and Ralated Test Waveforms. SAE Aerospace. USA, 2013. pp. 1-56.

4. SAE ARP 5416: 2013. Aircraft Lightning Test Methods. SAE Aerospace. USA, 2013. pp. 1-145.

5. Baranov M.I., Koliushko G.M., Kravchenko V.I., Nedzel'skii O.S., Dnyshchenko V.N. A Current Generator of the Artificial Lightning for Full-Scale Tests of Engineering Objects. Pribory i tehnika eksperimenta - Instruments and Experimental Technique, 2008, no.3, pp. 401-405. doi: 10.1134/s0020441208030123.

6. IEC 62305-1: 2010 «Protection against lightning. Part 1: General principles». Geneva, IEC Publ., 2010.

7. Available http://www.sgkarkas.ru/spravochnik/marochnik stalej/12h18n1 $\underline{\text { t }}$ (accessed 15 May 2013). (Rus).

8. Baranov M.I. Izbrannye voprosy elektrofiziki. Tom 2, Kn. 2: Teoriia elektrofizicheskikh effektov $i$ zadach [Selected topics of Electrophysics. Vol.2, Book 2. A theory of electrophysical effects and tasks]. Kharkiv, NTU «KhPI» Publ., 2010. 407 p. (Rus).

9. Karslou G., Eger D. Teploprovodnost' tverdykh tel / Per. s angl. [Heat conductivity of solids / Transl. from Eng.]. Moscow, Nauka Publ., 1964. 487 p. (Rus).

10. Dronov V.N., Serkov A.A. Komp'iuternaia programma dlja rascheta struktury elektrotermicheskogo vozdeistvija toka molnii na metallicheskuju obshivku / Svidetel'stvo o registratsii avtorskogo prava № 30557 ot 06.10.2009. Vydano gosudarstvennoi sluzhboi intellektual'noi sobstvennosti Ukrainy [Computer program for the calculation of structure of electrothermal action of current of lightning on the metallic edging / Testifying to registration of copyright no.30557 from 06.10.2009. It is given out government service intellectual property of Ukraine]. (Rus). 
11. Berzan V.P., Gelikman B.Yu., Guraevsky M.N., Ermuratsky V.V., Kuchinsky G.S., Mezenin O.L., Nazarov N.I., Peregudova E.N., Rud' V.I., Sadovnikov A.I., Smirnov B.K., Stepina K.I. Elektricheskie kondensatory $i$ kondensatornye ustanovki. Spravochnik [The electrical capacitors and condenser options. Directory]. Moscow, Energoatomizdat Publ., 1987, 656 p. (Rus).

12. Baranov M.I., Koliushko G.M., Kravchenko V.I., Nedzel'skiy O.S. High-voltage high-current generator air gaps of the current artificial lightning. Pribory i tekhnika eksperimentaInstruments and experimental techniques, 2008, no.6, pp. 58-62. (Rus).

13. Baranov M.I., Rudakov S.V. Development of new charts of capacitance-resistance defense of high-voltage capacitors of powerful capacity stores of energy from emergency currents. Elektrotekhnika i elektromekhanika - Electrical engineering \& electromechanics, 2015, no.6, pp.47-52. doi: 10.20998/2074272X.2015.6.08. (Rus).

14. Baranov M.I., Kravchenko V.I. Electrothermal resistance wire and cable to the aircraft to the striking action pulsed current lightning. Elektrichestvo - Electricity, 2013, no.10, pp. 7-15. (Rus).

\section{How to cite this article:}

Baranov M.I., Kniaziev V.V., Kravchenko V.I., Rudakov S.V. Results of calculation-experimental investigations of electro-thermal resistibility of sheet steel samples to action of rationed components of pulsed current of artificial lighting. Electrical engineering \& electromechanics, 2016, no.3, pp. 40-49. doi: 10.20998/2074-272X.2016.3.07. 